\title{
Turbulent heat transfer enhancement in tubular heat exchangers with different twisted tape inserts
}

\author{
S. H. Labib1, M. R. A. Himel1', J. I. Ali1', A. R. Mim¹', M. J. Hossain'1, A. K. Ghosh², A. Goswami1,2,* \\ ${ }^{1}$ Department of Mechanical and Production Engineering, Ahsanullah University of Science and Technology, Dhaka 1208, Bangladesh \\ 2 Department of Mechanical Engineering, Imperial College London, London SW7 2AZ, UK
}

\begin{abstract}
Experimental and numerical analyses are carried out to investigate the influence of twisted tape inserts on the heat transfer and the flow behavior in double tube heat exchangers. First, all the performance factors, namely the Nusselt number, friction factor, and thermal performance factor, were studied for a basic heat exchanger (BHE). Afterwards, twisted tapes with three different twist ratios $(7.5,6$, and 4.5$)$ were inserted inside the inner tube of the BHE, which resulted in three different modified heat exchangers (MHEs). For the numerical study, a 3D numerical model is developed with the $k-\varepsilon$ RNG turbulent model to visualize the flow and the heat transfer behavior inside the heat exchangers. In both studies, turbulent flow field is maintained, ranging Reynolds number from 15000 to 50000 . From the experimental result, an enhanced heat transfer, characterized by the performance factors, is found for all the MHEs compared to the BHE. The most enhanced thermal performance factor is achieved for the MHE with the lowest twist ratio. Finally, a good agreement between obtained numerical and experimental results reveals that the present numerical model can reliably predict the flow and heat transfer behavior in double tube heat exchangers.
\end{abstract}

ARTICLE HISTORY

Received: $14^{\text {th }}$ Nov 2020

Revised: $25^{\text {th }}$ Mar 2021

Accepted: $18^{\text {th }}$ May 2021

\section{KEYWORDS}

Basic heat exchanger; modified heat exchanger; twisted tape;

turbulent flow;

computational analysis.

\section{INTRODUCTION}

Heat exchangers have a diverse range of applications in industries such as power plants [1,2], air conditioning [3], chemical engineering $[4,5]$, aerospace engineering [6,7], and other scientific applications. In recent times, heat exchangers are enforced to become more and more efficient because of the increasing cost of materials and energy [8]. Several methods can be adopted to enhance the effectiveness of a heat exchanger. These methods are widely categorized into two groups: (i) active methods, and (ii) passive methods $[9,10]$. The active methods require external power to create vibration, electric or acoustic field, and fluid injection or suction to augment the heat transfer performance. In contrast, the passive methods use different types of devices like helical coils, circular discs, fins, twisted tapes, etc. to generate swirl flow, increase the fluid flow time in the conduit, increase the surface area, thus enhance the heat transfer rate of a heat exchanger in a relatively economic way. These passive methods have become the key attention for many researchers over the past decades. Researchers used helical wire coils [11-13], circular discs [14-16], and fins [17-20] as heat transfer enhancement tools inside heat exchangers. In a numerical study, Omidi et al. [21] used lobed cross-section helical coils to adopt passive heat transfer enhancement. It was observed that the helical coil with the maximum number of lobes results in the highest Nusselt number and lowest friction factor, and thus enhances the heat transfer rate. Yadav and Sahu [22] investigated the heat transfer from water to air in a double tube heat exchanger where helical surface discs are used as turbulators with different pipe diameter to disc diameter ratios. From the experiments, it was observed that the smallest diameter ratio gives a higher thermal performance for the heat exchanger. Researchers also investigated the use of nanofluids to augment the performance of heat exchangers [23-25]. Using the $\mathrm{Al}_{2} \mathrm{O}_{3}$ /water nanofluid, Han et al. [26] experimentally found that the heat transfer performance increases with an increase in the nanoparticle concentration in the nanofluid. Ravi et al. [27] used the $\mathrm{Fe}_{3} \mathrm{O}_{4}$ /water nanofluid along with twisted tape inserts as a heat transfer enhancement device, and found an improved thermal performance from the developed heat exchanger than a basic heat exchanger without the twisted tapes.

Extensive studies have been reported, both experimental and numerical, to assess the effectiveness of using twist tapes in a heat exchanger by evaluating the heat transfer augmentation and pressure drop in heat exchangers [28-41]. An inserted twisted tape stimulates the fluid flow between the wall and nucleus of the tube, which improves the mixing of fluid across the cross-section of the tube [28] and makes the thickness of the boundary layer thinner [34, 35]. These phenomena have made the modified heat exchanger advantageous over the basic heat exchanger with enhanced heat transfer rate and thermal efficiency as reported in the mentioned research papers. A numerical investigation was conducted by Eiamsa-ard et al. [36] using twisted tape inserts with clearance ratios of 0.0 to 0.3 in a circular tube, where twisted tape inserts with a lower clearance ratio resulted in a higher heat transfer rate. In this context, Bas and Ozceyhan [38] studied the pressure drop and heat transfer rate in a heat exchanger with twisted tapes with low clearance ratios of 0.0 to 0.03 . From this study, it was reported that not only the heat transfer rate is enhanced by the lower clearance ratio 
of twisted tapes, but the pressure drop also increases consequently, which eventually affects the performance of the heat exchanger. Mashoofi et al. [39] used axially perforated twisted tapes and found a higher thermal performance than simple twisted tape, for the turbulent fluid flow of Reynolds number ranging from 5000 to 15000. Similarly, Saysroy and Eiamsaard [40] have introduced a multi-channel twisted tape insert as a heat transfer augmentation device in a numerical study. The twisted tapes were varied on the number of channels (2 to 8 ) and twist ratios (2 to 4 ) for both laminar and turbulent flow fields. For the laminar case, twisted tape with two channels and 2.5 twist ratio exhibited better thermal performance, and for the turbulent flow case, twisted tape with two channels and the twist ratio of 3 resulted in the most enhanced heat transfer rate. Abolarin et al. [41] have experimentally explored the heat transfer and pressure drop characteristics using clockwise and counterclockwise twisted tapes in the transition flow region for constant heat flux conditions. Recently, Sivakumar et al. [42] have numerically compared the heat transfer for plain, triangular, and circular twisted tape inserts, where the circular twisted tape is found to perform best than the other two heat transfer enhancement devices. So far in the above-discussed studies, most of the researchers have investigated the heat transfer augmentation due to twisted tape inserts in the turbulent flow regime with the maximum Reynolds number limited to near about 20,000. Therefore, more analysis with twisted tape inserts is required to understand and manipulate the heat transfer and fluid flow phenomena in heat exchangers for higher turbulent flow cases.

In the light of the above circumstances, the present study emphasizes the experimental and numerical investigation of the thermal performance enhancement, the pressure-drop phenomena, and the fluid flow behavior in a double tube heat exchanger with twisted tape inserts for turbulent flow ranging from 15,000 to 50,000, which is a bit higher than the previously discussed analyses. Moreover, the current study prioritizes to design and fabricate a low-cost double tube heat exchanger with optimized heat transfer enhancement. Swirl flow generators such as twisted tapes with lower twist ratios are more complex to manufacture as well as costly. In this regard, twisted tapes with twist ratios of 7.5, 6 and 4.5 have been considered for assessing their effect on the thermal performance enhancement of the double tube heat exchanger. For this, first of all, the experimental study has been conducted with the basic double tube heat exchanger (BHE), and with the modified heat exchangers (MHEs) after inserting twisted copper tape inserts with three different twist ratios (7.5, 6 and 4.5). Subsequently, the experimental conditions of the BHE and MHEs have been simulated numerically. Finally, the numerical results are compared with the experimental findings to check the reliability of the developed numerical model in predicting the heat transfer augmentation due to twisted tape insertion.

\section{EXPERIMENTAL SETUP}

Shown in Figure 1, is the schematic diagram of the experimental setup that includes a double tube heat exchanger with twisted tape inserts. In this setup, both hot and cold stream is water and it is supplied by two 1.5 hp power pumps respectively. The flow rate of both hot and cold fluids is controlled by the ball valve, and the flow rate is measured by employing volumetric flowmeters. A copper pipe with 1 inch external diameter and $11.5 \mathrm{ft}(\sim 350 \mathrm{~cm})$ long, is used as the tube and a PVC pipe of 2-inch internal diameter is used as the shell whilst the length of the shell is kept as same as the tube. There is a total number of eight pen-type thermocouples are mounted on the apparatus to determine the temperatures of the hot fluid, cold fluid, and tube wall at different positions along the length of the heat exchanger. The hot fluid is heated by a $1 \mathrm{~kW}$ portable water heater in a chamber. Twisted tapes made of copper material was used as a turbulator to evaluate the thermal performance enhancement in the heat exchanger. Three different twist ratios of 7.5, 6, and 4.5 are employed to analyze the thermal effect from the heat exchanger shown in Figure 2. A total number of 13 twisted tapes are inserted in the copper tube for each twist ratio. The length, width, and thickness of each tape are $25 \mathrm{~cm}, 2 \mathrm{~cm}$, and 0.3 $\mathrm{cm}$, respectively. Two pressure gauges are used to find the pressure drop across the tube, due to the insertion of twisted tapes in the tube which interrupts the normal flow of fluid.

Reynolds numbers ranging from 15000 to 50000 are maintained in terms of fluid flow rate during the experiments. First, hot water and cold water are brought to the desired temperature. The temperature of the cold water is generally maintained at room temperature. The hot water temperature is about $30^{\circ} \mathrm{C}$ more than cold water. The heater connection is turned off before starting the procedure. Ball valves are regulated as per the desired flowrate. The flowrate for the coldwater circuit has always been maintained at a fixed flowrate. Two pumps are started at the same time. Data is taken from all eight (8) thermocouples. Two of them for the cold-water inlet and outlet temperature, two of them for the hot-water inlet and outlet temperature, and the other four thermocouples for the wall temperature of the inner copper tube at various positions as shown in Figure 1. In addition, the pressure drop in the tube has been obtained from the two pressure gauges. The setup has been in operation for 30 minutes for every data collection session, and data are collected at every single minute interval. The experimental procedures are all the same for the basic and modified HEs. Besides, uncertainty analysis is conducted with $95 \%$ confidence in data acquisition using the measuring instruments. The maximum errors in obtained data of the measure parameters using the instruments are shown in Table 1. 
Table 1. Uncertainties in obtained data

\begin{tabular}{lll}
\hline Measured parameter & Instrument & Maximum error $(\%)$ \\
\hline Temperature $\left({ }^{\circ} \mathrm{C}\right)$ & Thermocouple & \pm 1 \\
Pressure $(\mathrm{Pa})$ & Pressure gage & \pm 0.25 \\
Flow rate $\left(\mathrm{m}^{3} / \mathrm{hr}\right)$ & Volumetric flow meter & \pm 0.5 \\
Length $(\mathrm{mm})$ & Meter Scale & \pm 0.5 \\
\hline
\end{tabular}

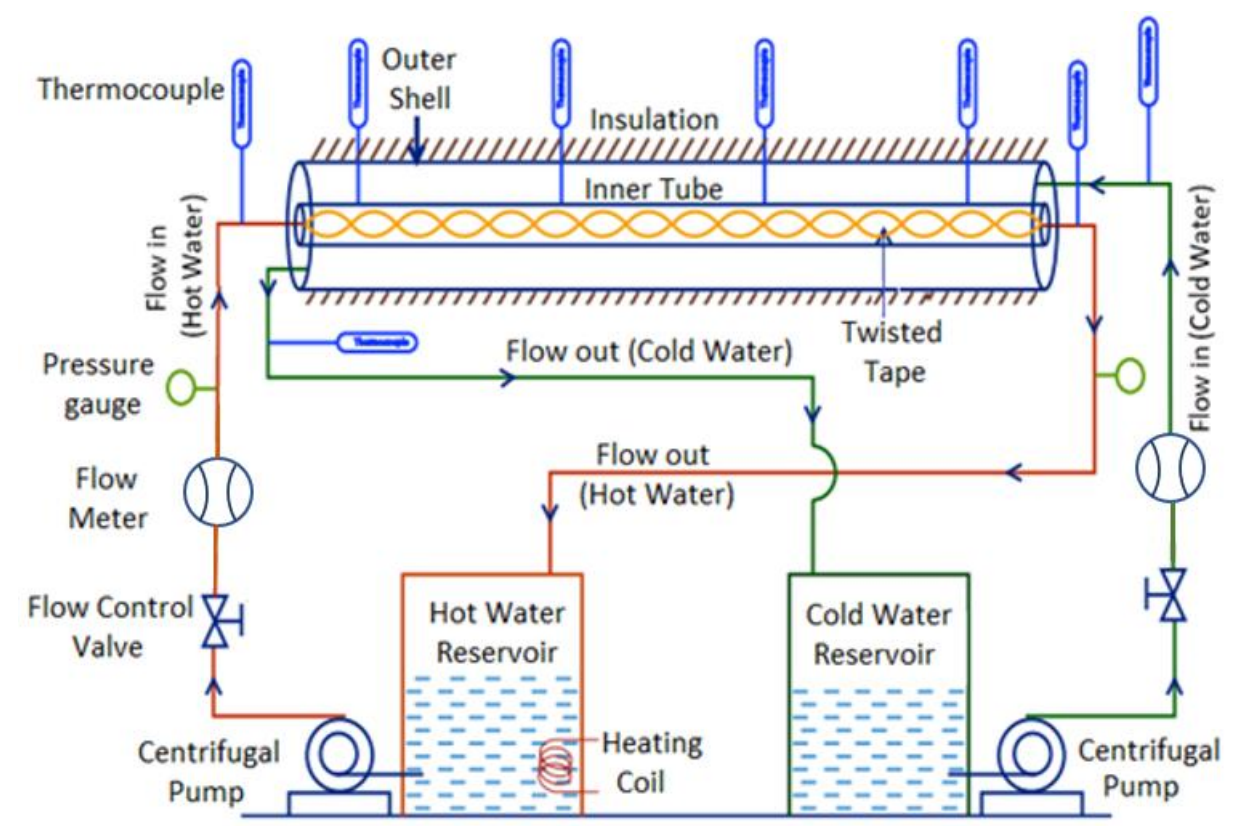

Figure 1. Schematic diagram of the experimental setup

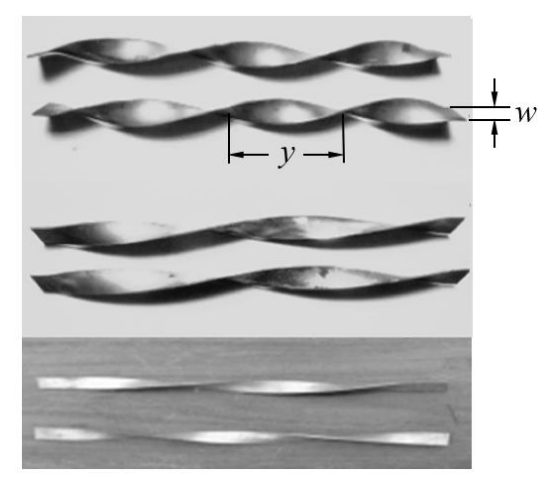

Figure 2. Different twist ratios in copper tapes $[y / w=4.5,6$, and 7.5 (from top to bottom)]. (All the twisted tapes are not presented to their actual scales)

\section{DATA ANALYSIS}

In this present study, all calculations have been done for the basic heat exchanger and the modified heat exchanger with different twisted ratios. For the steady-state condition, the convection heat transfer rate $\left(Q_{\text {conv }}\right)$ is considered as the heat loss from the hot fluid $\left(Q_{H}\right)$ in a tube and can be expressed as follows:

$$
Q_{H}=Q_{\text {conv }}
$$

$$
\text { where, } Q_{H}=m C_{p, H}\left(T_{o}-T_{i}\right)
$$


with $m$ as the mass flow rate of the hot fluid, $C_{p, H}$ as the heat capacity of water, and $T_{i}$ and $T_{o}$, respectively, as the inlet and outlet temperature of the hot fluid.

$Q_{\text {conv }}$ from the copper tube can be determined as:

$$
Q_{\text {conv }}=h A\left(T_{w}-T_{b}\right)
$$

with $A$ as the surface area of the inner copper tube. The bulk fluid temperature $\left(T_{b}\right)$ is obtained by:

$$
T_{b}=\frac{T_{o}+T_{i}}{2}
$$

and, the average wall temperature $\left(T_{w}\right)$,

$$
T_{w}=\frac{\sum t_{w}}{4}
$$

with $t_{w}$ as the local wall temperature on the hot tube. $T_{w}$ is calculated from the four $t_{w}$ values obtained from the thermocouples.

The heat transfer coefficient $(h)$ is calculated as:

$$
h=\frac{m C_{p, H}\left(T_{o}-T_{i}\right)}{A\left(T_{w}-T_{b}\right)}
$$

The heat transfer can be estimated in terms of Nusselt Number $(\mathrm{Nu})$ as [43]:

$$
N u=\frac{h D}{k}
$$

The friction factor $(f)$ is determined by [43]:

$$
f=\frac{\Delta P}{\left\{\left(\frac{L}{D}\right)\left(\frac{\rho V^{2}}{2}\right)\right\}}
$$

\begin{tabular}{|c|c|c|c|c|c|c|c|c|}
\hline \multirow{2}{*}{$\begin{array}{c}\text { Reynolds } \\
\text { Number, } \\
\text { Re }\end{array}$} & \multicolumn{4}{|c|}{ Nusselt Number, $\mathrm{Nu}$} & \multicolumn{4}{|c|}{ Friction Factor, $f$} \\
\hline & BHE & $\begin{array}{c}\text { MHE } y / w \\
=7.5\end{array}$ & $\begin{array}{c}\text { MHE } y / w \\
=6.0\end{array}$ & $\begin{array}{c}\text { MHE } \\
y / w=4.5\end{array}$ & BHE & $\begin{array}{c}\text { MHE } y / w \\
=7.5\end{array}$ & $\begin{array}{c}\text { MHE } y / w \\
=6\end{array}$ & $\begin{array}{c}\text { MHE } y / w \\
=4.5\end{array}$ \\
\hline 50000 & 56.23 & 60.14 & 64.76 & 80.11 & 0.022 & 0.042 & 0.059 & 0.070 \\
\hline 42988 & 50.50 & 54.35 & 59.57 & 75.20 & 0.027 & 0.049 & 0.066 & 0.080 \\
\hline 26512 & 44.09 & 49.18 & 52.59 & 62.40 & 0.039 & 0.073 & 0.092 & 0.117 \\
\hline 16963 & 39.63 & 42.07 & 45.19 & 51.93 & 0.047 & 0.091 & 0.137 & 0.168 \\
\hline
\end{tabular}

where $\Delta P$ denotes the pressure drop across the hot tube. A summary of the obtained experimental data is shown in Table 2.

Table 2. Experimental data summary

\section{COMPUTATIONAL MODEL}

Physical Model

The 3D numerical model of the test section (see Figure 3.) was developed by using ANSYS Fluent (Version 18.1 Academic) to predict the flow behavior, pressure drop, and heat transfer performance of the heat exchanger, and to compare the computational findings with the experimental results. Two circular fluid domains, a circular fluid domain for the hot fluid and an annular fluid domain for the cold fluid, were created along the tube, and the twisted tape in this model. After that, tetrahedron meshing was applied with the default mesh tool for the hot fluid domain. The cold fluid domain, the tube, and the twisted tapes were firmly meshed using the mesh control tool that includes the edge sizing, and the mapped face meshing (shown in Figure 4). The outer tube was not created as the wall of the cold fluid domain was retained adiabatic. 


\section{Boundary Condition}

The mass flow inlet boundary condition was implemented at the inlet of both hot and cold fluids. Additionally, the turbulent intensity at the inlet was considered 5\% for both hot and cold fluid, and the hydraulic diameter for the hot and cold fluid was $0.0254 \mathrm{~mm}$ and $0.0338 \mathrm{~mm}$, respectively. Besides, the temperature difference between the inlets of the hot and cold fluid was kept identical to the experimental conditions. At the outlet, the pressure outlet condition was applied with zero-gauge pressure for both fluids. Afterwards, the stationary inner tube wall was coupled with both fluids via system coupling, and the outer tube wall was considered as an adiabatic wall. Subsequently, the wall between the twisted tape inserts and the hot fluid domain was also assumed adiabatic.

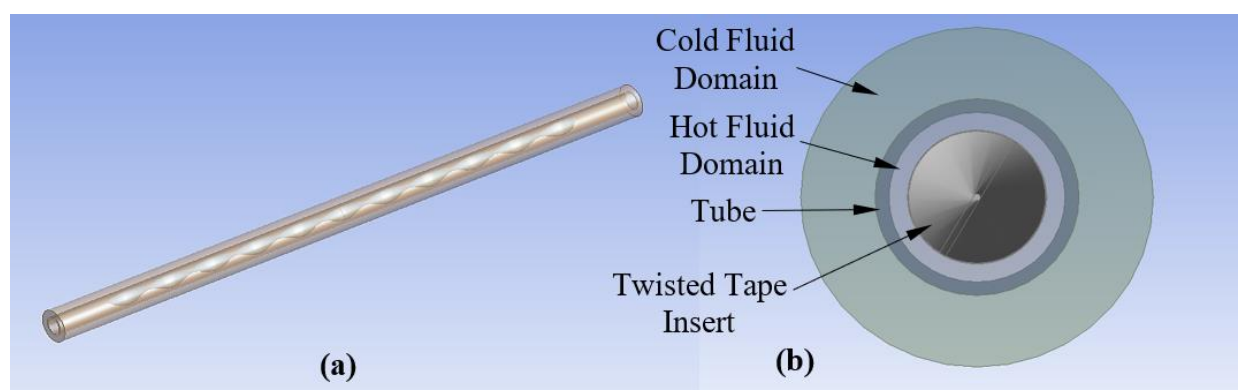

Figure 3. 3D model of the test section: (a) isometric view and (b) cross-sectional view

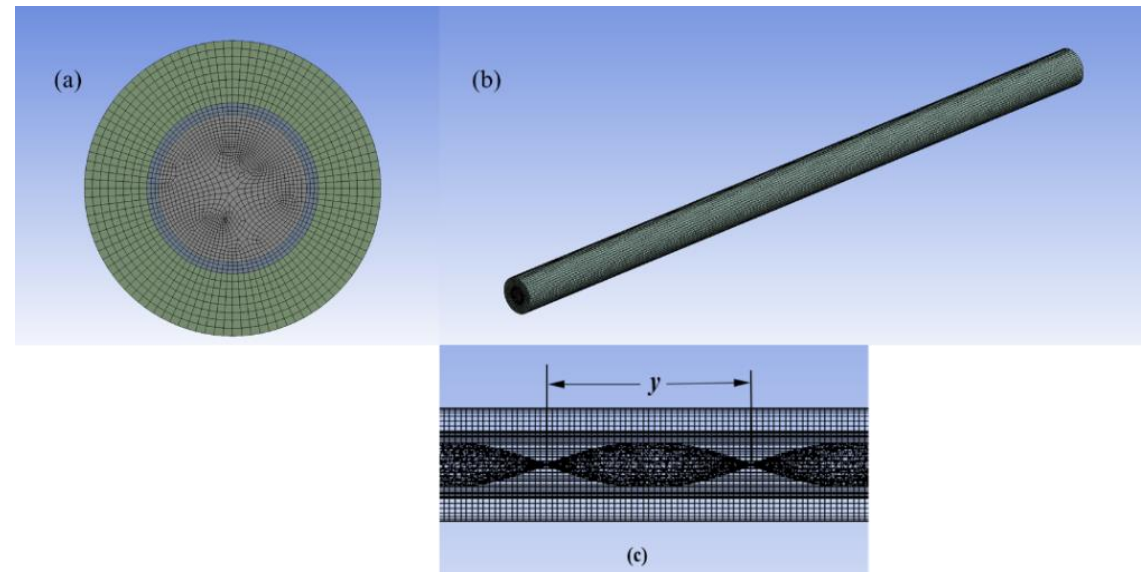

Figure 4. Illustration of the developed grid system: (a) cross-section, (b) global 3-D model and (c) side view

\section{Mathematical Model}

To predict the flow characteristic and the heat transfer phenomena in the double tube heat exchanger with twisted tape inserts in its inner tube, some reasonable assumptions were made to simplify the following governing equations: the continuity equation, the momentum equation, and the equation of energy conservation. The assumptions are as follows: (1) steady, incompressible, and turbulent flow, (2) negligible thermal radiation, natural convection, and body forces, and (3) temperature-independent thermo-physical fluid properties. Based on these assumptions, the continuity, the momentum, and the energy equations can be expressed as follows:

Continuity equation:

$$
\frac{\partial u}{\partial x}+\frac{\partial v}{\partial y}+\frac{\partial w}{\partial z}=0
$$

Momentum equations

$x$-momentum:

$$
\left(\bar{u} \frac{\partial \bar{u}}{\partial x}+\bar{v} \frac{\partial \bar{u}}{\partial y}+\bar{w} \frac{\partial \bar{u}}{\partial z}\right)+\left(\frac{\partial}{\partial x}\left(\overline{u^{\prime 2}}\right)+\frac{\partial}{\partial y}\left(\overline{u^{\prime} v^{\prime}}\right)+\frac{\partial}{\partial z}\left(\overline{u^{\prime} w^{\prime}}\right)\right)=-\frac{1}{\rho} \frac{\partial p}{\partial x}+\vartheta \nabla^{2} \bar{u}
$$


$y$-momentum:

$$
\left(\bar{u} \frac{\partial \bar{v}}{\partial x}+\bar{v} \frac{\partial \bar{v}}{\partial y}+\bar{w} \frac{\partial \bar{v}}{\partial z}\right)+\left(\frac{\partial}{\partial x}\left(\overline{v^{\prime 2}}\right)+\frac{\partial}{\partial y}\left(\overline{u^{\prime} v^{\prime}}\right)+\frac{\partial}{\partial z}\left(\overline{v^{\prime} w^{\prime}}\right)\right)=-\frac{1}{\rho} \frac{\partial p}{\partial y}+\vartheta \nabla^{2} \bar{v}
$$

Z-momentum:

$$
\left(\bar{u} \frac{\partial \bar{w}}{\partial x}+\bar{v} \frac{\partial \bar{w}}{\partial y}+\bar{w} \frac{\partial \bar{w}}{\partial z}\right)+\left(\frac{\partial}{\partial x}\left(\overline{w^{\prime 2}}\right)+\frac{\partial}{\partial y}\left(\overline{u^{\prime} w^{\prime}}\right)+\frac{\partial}{\partial z}\left(\overline{v^{\prime} w^{\prime}}\right)\right)=-\frac{1}{\rho} \frac{\partial p}{\partial z}+\vartheta \nabla^{2} \bar{w} \rho \frac{d \vec{v}}{d t}=\nabla \sigma
$$

Energy equation:

$$
\bar{u} \frac{\partial \bar{T}}{\partial x}+\bar{v} \frac{\partial \bar{T}}{\partial y}+\bar{w} \frac{\partial \bar{T}}{\partial z}=\alpha \nabla^{2} \bar{T}-\left(\frac{\partial}{\partial x}\left(\overline{u^{\prime} T^{\prime}}\right)+\frac{\partial}{\partial y}\left(\overline{v^{\prime} T^{\prime}}\right)+\frac{\partial}{\partial z}\left(\overline{w^{\prime} T^{\prime}}\right)\right)
$$

The Renormalization group (RNG) $k-\varepsilon$ turbulence model was implemented for the turbulent flow model, which has shown a quite good agreement with experimental results $[34,36,40,44]$. The $k$ and $\varepsilon$ equations are:

$$
\begin{gathered}
\frac{\partial}{\partial x_{i}}\left(\rho k u_{i}\right)=\frac{\partial}{\partial x_{j}}\left(\alpha_{k} \mu_{e f f} \frac{\partial k}{\partial x_{j}}\right)+G_{k}-\rho \varepsilon+S_{k} \\
\frac{\partial}{\partial x_{i}}\left(\rho \varepsilon u_{i}\right)=\frac{\partial}{\partial x_{j}}\left(\alpha_{\varepsilon} \mu_{e f f} \frac{\partial \varepsilon}{\partial x_{j}}\right)+C_{1 \varepsilon} G_{k}-C_{2 \varepsilon} \rho \frac{\varepsilon^{2}}{k}-R_{\varepsilon}+S_{\varepsilon}
\end{gathered}
$$

where, $\rho \varepsilon$ is the destruction rate, and $G_{k}$ is the rate of turbulent kinetic energy generation which is determined as:

$$
G_{k}=-\rho \overline{u_{i}^{\prime} u_{j}^{\prime}} \frac{\partial u_{j}}{\partial x_{i}}
$$

Near a tube wall, the boundary values were defined with the enhanced wall treatment method for the turbulent quantities. The constants $C_{1 \varepsilon}=1.42$ and $C_{2 \varepsilon}=1.68$ were employed in the present turbulent transport model.

The semi-implicit pressure linked equation method (SIMPLE) was adopted as the pressure-velocity coupling method for this numerical study. The first order discretization criteria for turbulence kinetic energy and dissipation and the secondorder discretization were defined for the continuity, momentum, and energy. For all the residuals, a convergence criterion was set to $10^{-6}$.

\section{VALIDATION OF THE STUDY}

In this study, the experimentally and numerically obtained Nusselt number friction factor values for the basic heat exchanger (BHE) are compared with the Dittus-Boelter correlation [43] and Blasius Equation [43] respectively,

$$
\begin{gathered}
N u=0.023 \operatorname{Re}^{0.8} \operatorname{Pr}^{0.3} \\
f=0.316 \operatorname{Re}^{-0.25}
\end{gathered}
$$

Shown in Figure 5 is the variation of Nusselt number as a function of Reynolds number for the present study (experimental and numerical), and that is for the Dittus-Boelter empirical correlation. For each case, with the increase of fluid flow velocity (characterized by Reynolds number), the heat transfer (characterized by Nusselt number) also increases. In addition, the experimental and numerical results display a good agreement with the Dittus-Boelter correlation. For all cases, the results from the numerical analysis are higher than the experimental findings because there were always some inevitable minor heat losses through insulations during experiments, while the numerical solutions assumed perfect adiabatic boundary conditions for insulated walls. Figure 6 shows the variation of friction factor with respect to Reynolds number for the conducted experimental and numerical investigations along with Blasius equation for friction factor. The maximum deviation of the friction factor for the experimental and numerical study is about $4 \%$ and $9 \%$, respectively, from that for the Blasius equation. 


\section{Grid Sensitivity Test}

To verify the grid independence of the numerical model a grid sensitivity test is conducted in the present investigation. The grid dependency test result for the basic heat exchanger (BHE) is shown in Figure 7; where for the 223500 elements, Nusselt number has been found about 40 . Considering, the converging time and the precession of the solution, the number of the element for BHE is kept at 223500. Furthermore, in the case of the modified heat exchangers (MHEs), 241000, 260000 and 288000 elements are selected for twist ratios 7.5, 6 and 4.5, respectively.

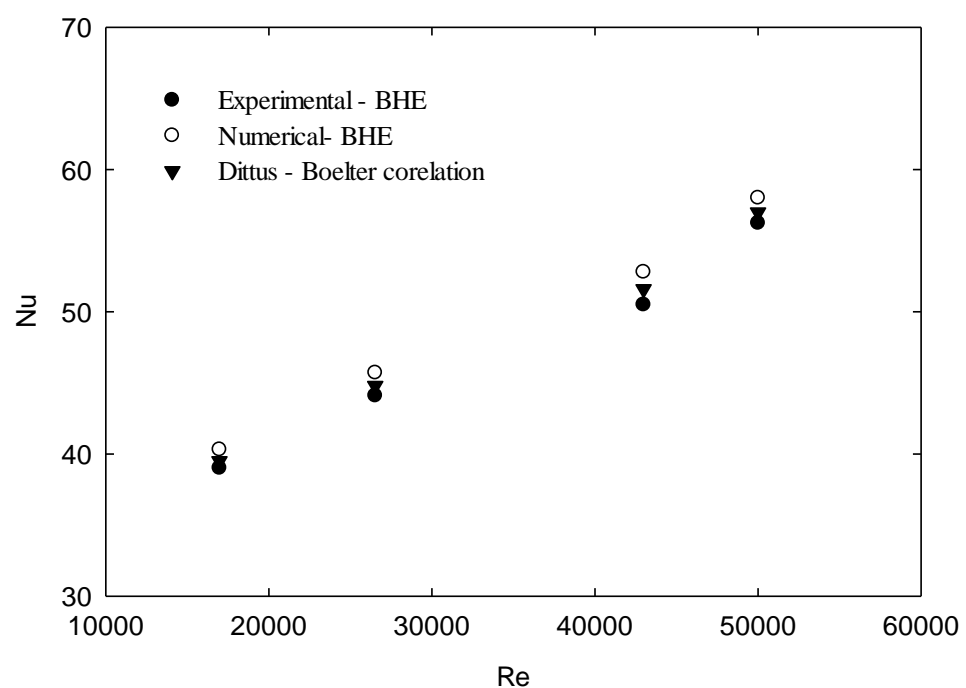

Figure 5. Variation of Nusselt number $(\mathrm{Nu})$ with Reynolds number $(\mathrm{Re})$ for the basic heat exchanger (BHE)

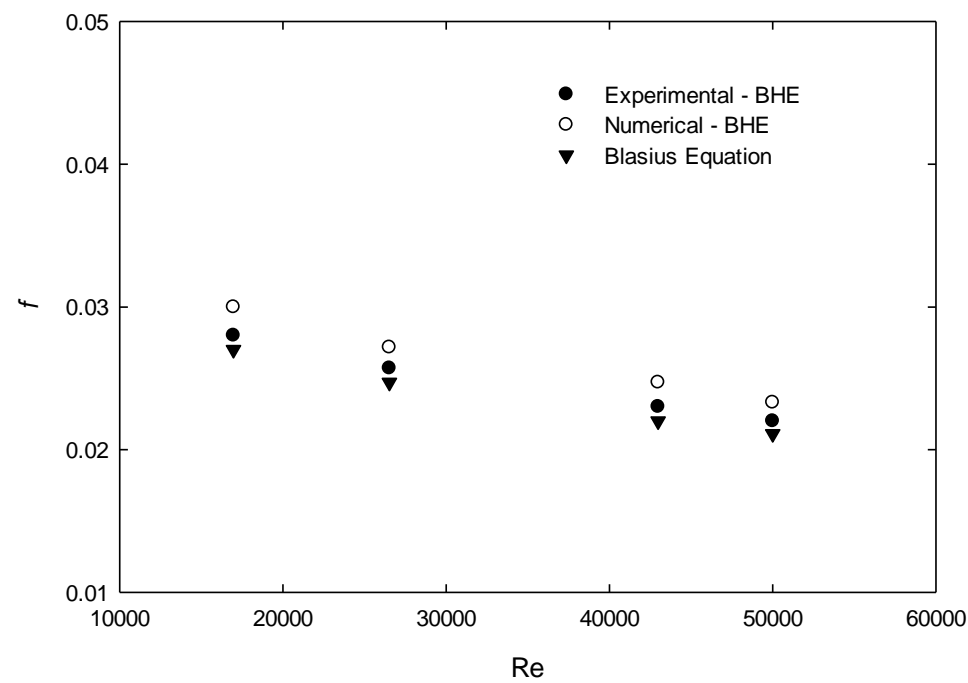

Figure 6. Variation of friction factor $(f)$ with Reynolds number (Re) for the basic heat exchanger (BHE) 


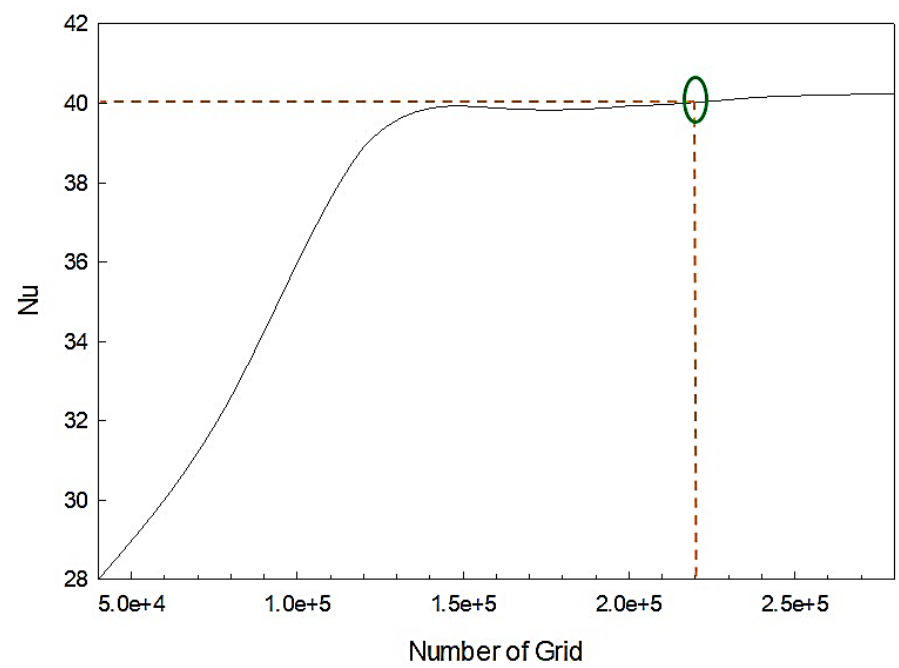

Figure 7. Grid dependency test for basic heat exchanger (BHE)

\section{RESULTS AND DISCUSSION}

\section{Flow Characteristics}

The insertion of twisted tapes inside the inner copper tube causes a smaller annular flow area for the hot fluid than in the basic heat exchanger. With the decrease of flow area, the flow velocity increases. Twisted tape generates secondary flow inside the copper tube along with the interruption of normal fluid flow. Turbulence is caused by higher flow velocity and twisted tapes, accompanying secondary fluid flow causes an increase in the heat transfer. Figure 8 . shows the streamlines for the basic heat exchanger and the modified heat exchanger with twist ratios of 7.5, 6, and 4.5, respectively. This figure illustrates the scenario of the swirl flow inside the inner copper tube of the heat exchanger. For the basic heat exchanger, there is no secondary flow that means no swirling of the hot fluid. However, in the cases of the modified heat exchanger, with decreasing twist ratio the swirling of the hot fluid increased. Due to higher swirling in the modified heat exchanger with a twist ratio of 4.5 , the hot fluid is contained inside the copper tube a bit longer time than the other heat exchangers, resulting in increased heat transfer. The velocity contours of the basic heat exchanger (BHE) and modified heat exchangers (MHEs) are demonstrated in Figure 9. From this figure, it is understandable that the velocity of the hot fluid increased due to the insertion of twisted tapes as these twisted tape inserts decrease the flow area. For the case of the MHE with the twist ratio of 4.5, a higher velocity region is obtained compared to other twist ratios. On the other hand, the velocity contour of the cold fluid in the annular tube remains the same for all the heat exchangers. The twisted tapes with a lower twist ratio induce higher turbulent kinetic energy (TKE) in the fluid flow through the tube as shown in Figure 10 , which eventually generate higher swirling in the fluid flow inside the tube. A lower twist ratio in a twisted tape insert means the number of turns in the insert is higher with a smaller pitch length. Therefore, the twisted tape inserts with a lower twist ratio generate more turbulence in fluid flow than that with the twisted tape with higher twist ratios. From Figure 10, the lowest turbulent kinetic energy is found in the BHE (the heat exchanger without twisted tape), while the maximum turbulent kinetic energy is found in the MHE with twisted tapes of 4.5 twist ratio. It is evident that the twist ratio of twisted tape inserts has a significant impact on generating turbulence in the flow field which in the end succors to enhance the heat transfer. 
(a) Basic $\mathrm{HE}$
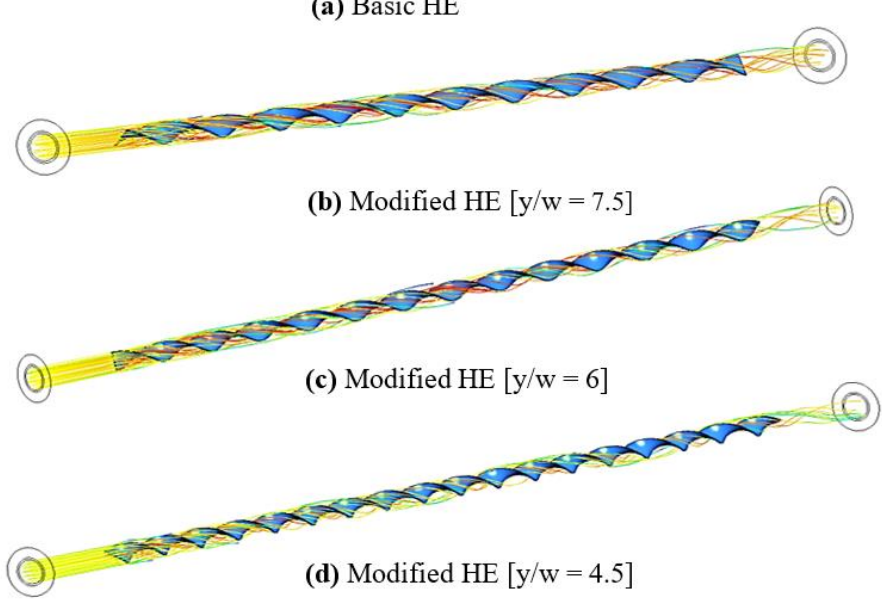

Figure 8. Streamlines of hot fluid domain inside the copper tube with twisted tape

(a)

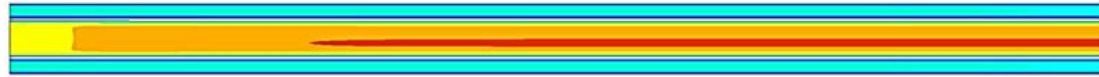

(b)

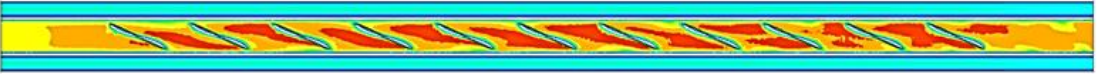

(c)

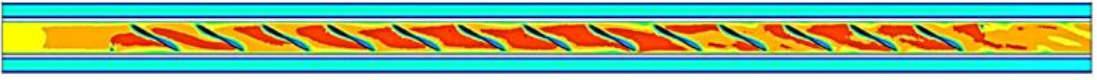

(d)
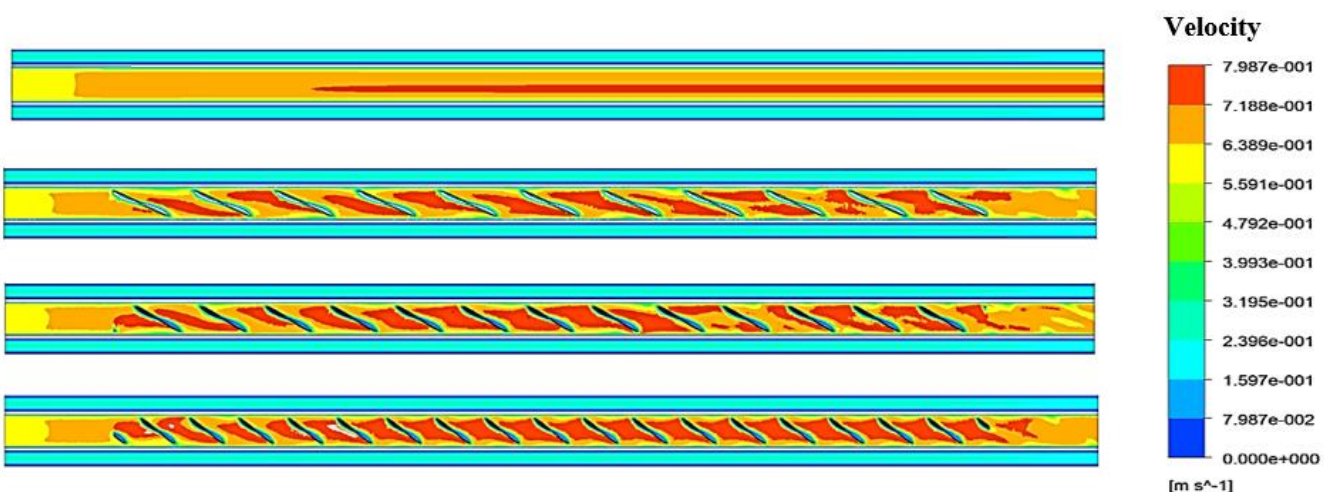

Figure 9. Velocity field of HEs: (a) Basic HE, (b) Modified HE $[y / w=7.5]$, (c) Modified HE [ $y / w=6]$ and (d) Modified HE $[y / w=4.5]$

(a)

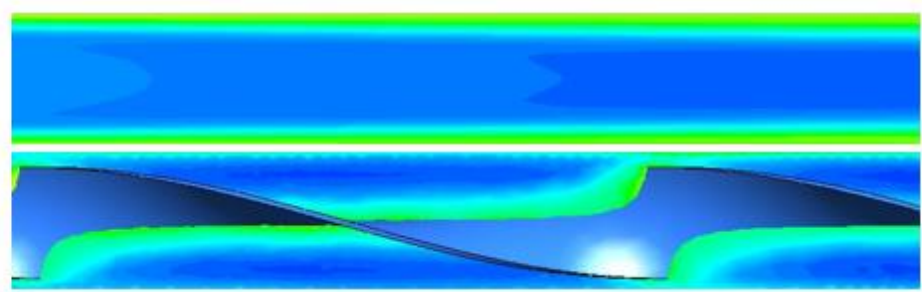

\section{Turbulent Kinetic Energy Contour}

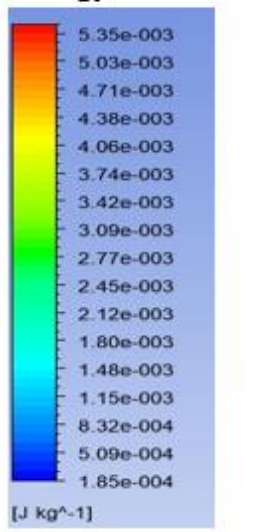

Figure 10. Turbulent kinetic energy contours of HEs: (a) Basic HE, (b) Modified HE [ $y / w=7.5]$, (c) Modified HE $[y / w=6]$ and (d) Modified HE $[y / w=4.5]$ 


\section{Heat Transfer Characteristics}

The variation of Nusselt number $(\mathrm{Nu})$ as a function of Reynolds number $(R e)$ for modified HEs with three different twist ratios along with basic HE is shown in Figure 11. The $N u$ is higher in the MHE with a twist ratio of 4.5 for both experimental and numerical study, than the BHE, and the other MHEs for different mass flow rates of hot water. - The insertion of twisted tape increases the turbulent intensity of the flow through the tube (as depicted in Figure 10) and interrupts the thermal boundary layer that results in a better mixture of the fluid inside the tube, which increases the convective heat transfer (characterized by $\mathrm{Nu}$ ). It also shows the linear variation of $\mathrm{Nu}$ along with $\mathrm{Re}$ for both BHE and MHEs. Besides, the developed numerical model gives a reliable prediction of the experimental scenario for all the cases as revealed in Figure 11.

Figure 12. displays the variation of the Nusselt number ratio $\left(\mathrm{Nu} / \mathrm{Nu} u_{o}\right.$; the ratio of MHE's Nusselt number $(\mathrm{Nu})$ to that of BHE $\left(N u_{o}\right)$ ) with Reynolds number for all the MHEs. This figure demonstrates a good agreement of the numerical results with the experimental ones and an enhanced heat transfer rate in the modified HEs. In comparison with the BHE, the augmentation of heat transfer in the MHEs with twist ratios of 7.5, 6, and 4.5 are about $18 \%, 27 \%$, and $56 \%$, respectively. While the results for the twist ratios of 7.5 and 6 are relatively closer, a significant increase is observed for the case with a twist ratio of 4.5. It is to be mentioned that the tape thickness $(w)$ was constant for all cases and the pitch length $(y)$ of the tapes were varied to achieve different twist ratios. A change in twist ratio from 7.5 to 6 led to a $20 \%$ decrease in the pitch length, while a subsequent change in twist ratio from 6 to 4.5 led to a $25 \%$ decrease in the pitch length. Therefore, the effect of a change in twist ratio from 6 to 4.5 led to a more increased number of turns in the tapes and generate a more complex flow pattern inside the tube. This complex flow pattern includes an induced secondary flow as a swirl flow in the fluid mainstream, and owing to this complex flow pattern, the flow resistance and heat transfer are both improved significantly with a decrease in the twist ratio. The twisted tape inserts disturb the thermal boundary layer and enhance turbulent intensity, which results in higher convective heat transfer in modified HEs than the Basic HE. Shown in Figure 13 are the temperature profiles at the outlet of the BHE and MHEs for a Reynolds number of 35000 for the hot fluid. As illustrated in this figure, the temperature distribution at the outlet of the MHEs is more uniform than the BHE because of the insertion of twisted tape inserts. This eventually reduced the circumferential temperature gradient. The boundary layer disruption and the mixing of the hot fluid in the inner tube as a result of the generated swirl flow enhances both the heat transfer and the circumferential temperature differences. Due to the higher heat transfer rate, the MHE with a twist ratio of 4.5 possesses a more uniform temperature contour at the outlet of hot fluid. Conversely, the BHE has a nonuniform temperature field at the outlet of hot fluid.

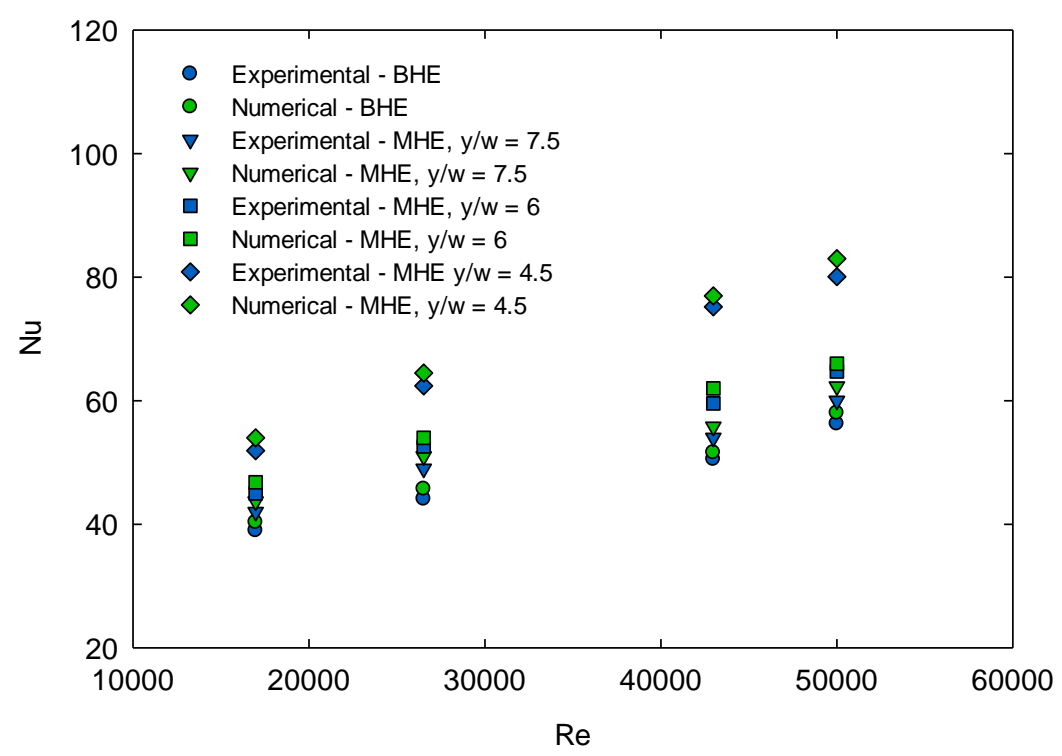

Figure 11. Variation of $N u$ as a function of Re for the BHE and MHEs 


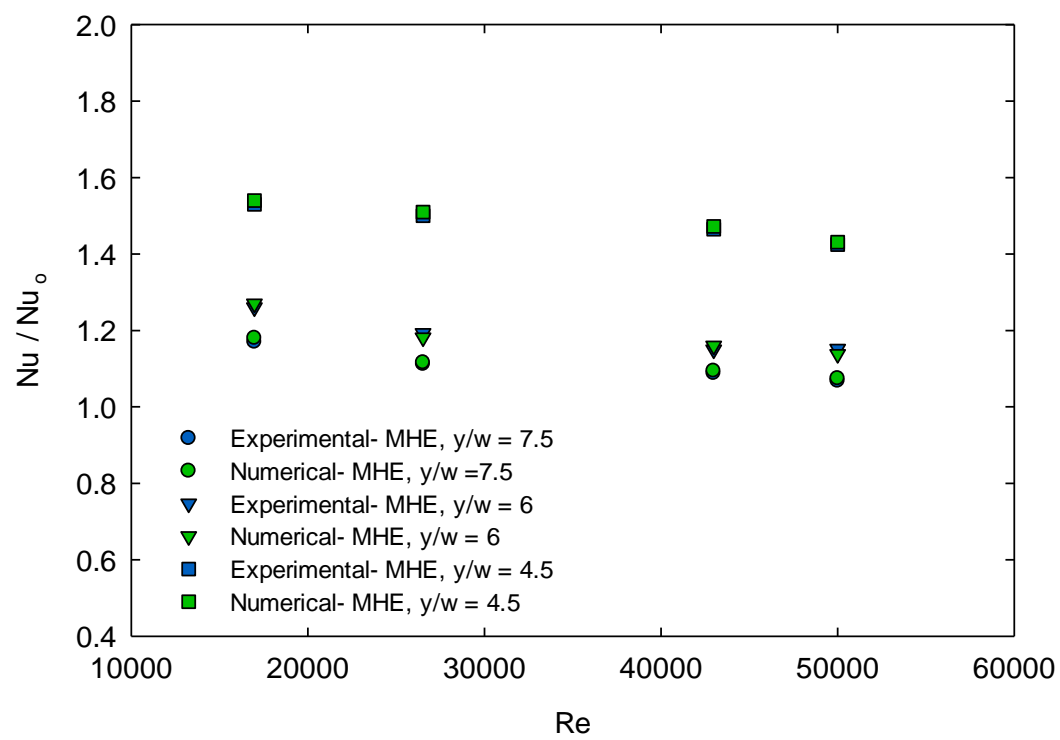

Figure 12. Variation of Nusselt number ratio $\left(N u / N u_{o}\right)$ as a function of Reynolds number $(R e)$ for the modified heat exchangers (MHEs)

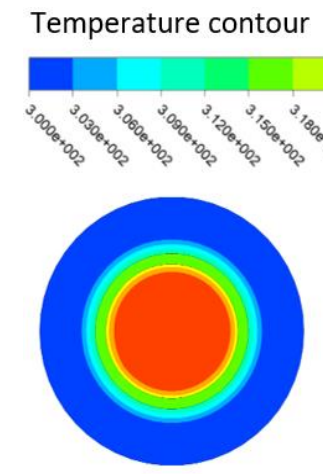

(a) Basic HE

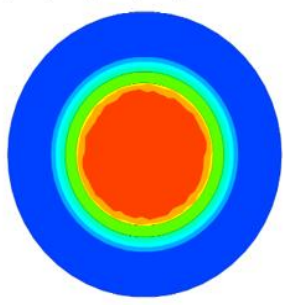

(b) Modified HE $[\mathrm{y} / \mathrm{w}=7.5]$

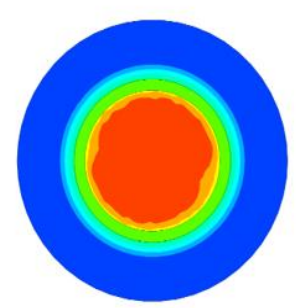

(c) Modified HE $[\mathrm{y} / \mathrm{w}=6]$

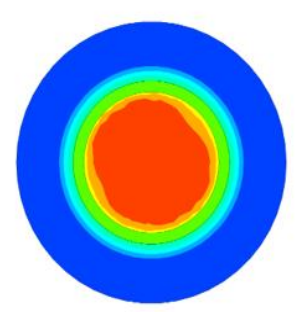

(d) Modified HE $[\mathrm{y} / \mathrm{w}=4.5]$

Figure 13. Temperature profile at the outlet of heat exchangers at $R e=35000$

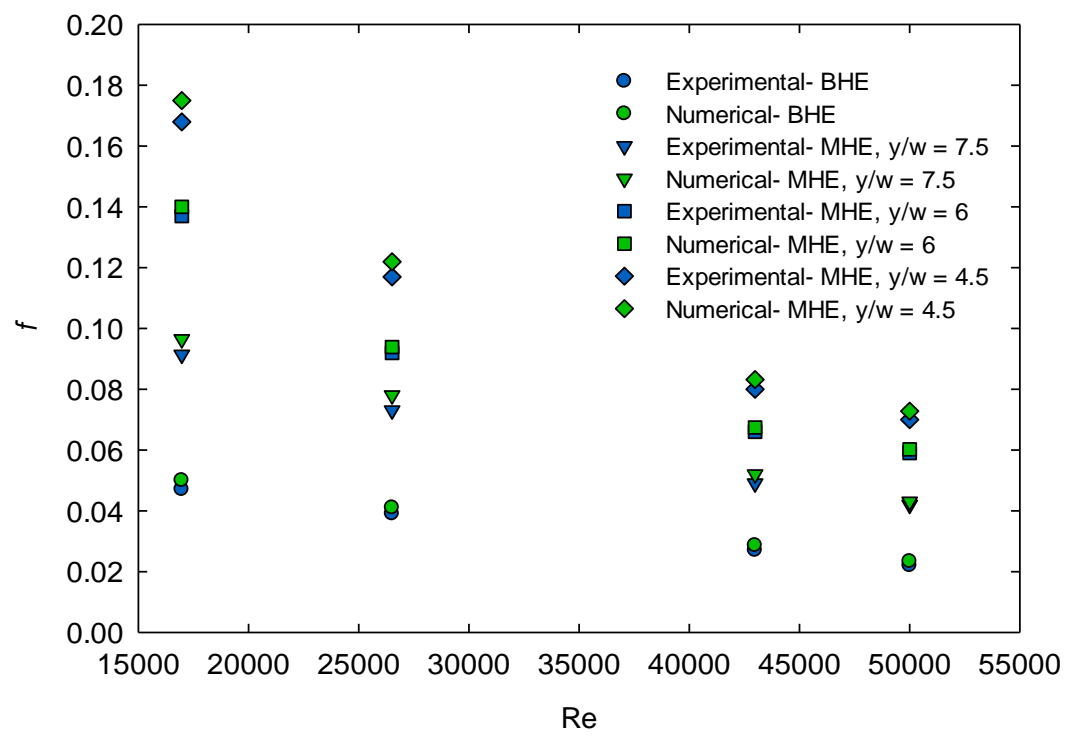

Figure 14. Variation of friction factor with $R e$ for the BHE and MHEs 


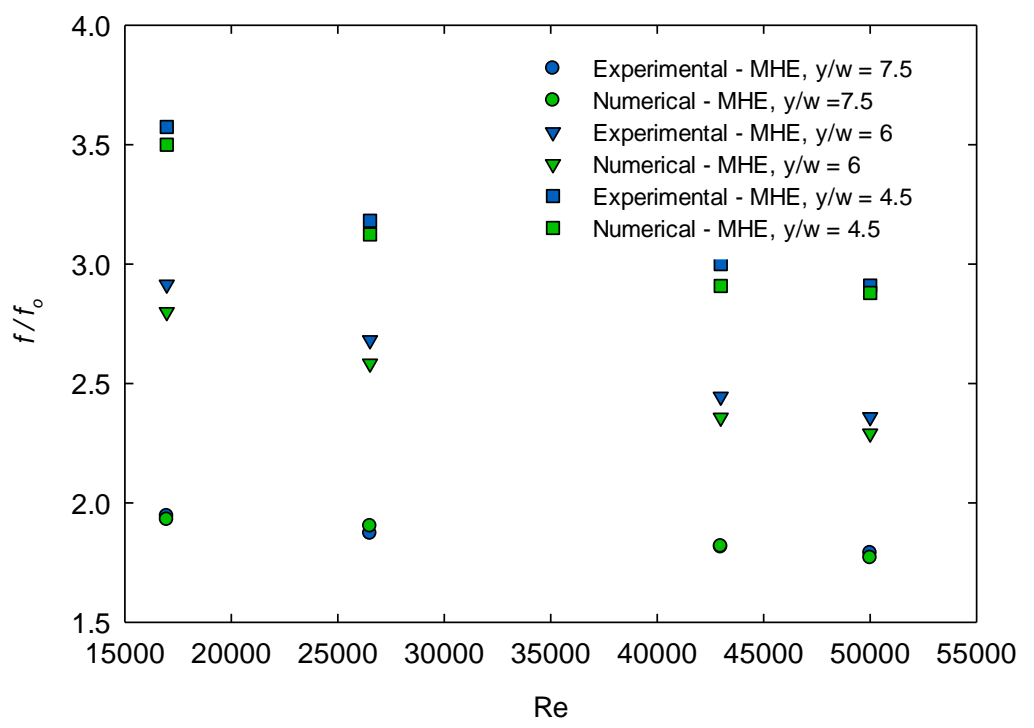

Figure 15. Variation of friction factor ratio with Re for the BHE and MHEs

\section{Friction Factor Characteristics}

Figure 14. shows the influence of the twist ratio of the twisted tape inserts on the friction factor. Here, the modified heat exchanger with a twist ratio of 4.5 results in the higher friction factor for both numerical and experimental investigations. From this figure, it is understandable that at the low Reynolds number friction factor is higher and on the other hand friction factor reduces with an increase of Reynolds number. This trend is identical for all the heat exchangers in both experimental and simulated investigations. Figure 15. reveals the variation of the friction factor ratio $\left(f / f_{o}\right)$, the ratio of the MHE's friction factor $(f)$ to that of the BHE $\left(f_{0}\right)$, with respect to Reynolds number. In comparison to the basic HE, the maximum amount of friction factor increases by about $190 \%, 290 \%$, and $350 \%$ for the modified HEs with the twist ratios of 7.5, 6, and 4.5, respectively. Shown in Figure 16 are the pressure contours for all the heat exchangers which narrate that the maximum pressure drop occurs at the modified $\mathrm{HE}$ with a twist ratio of 4.5 and the minimum pressure drop occurs in the basic HE. Additionally, it is experimentally observed that the pressure drop inside a heat exchanger increases with the decrease in the twist ratio of the inserts. Since the fluid is forced to flow a longer path along with the twisted tape profile in MHEs compared to BHEs, the pressure drops are higher at the MHEs. For the twisted tapes with the lower twist ratios, the path is longer than the heat exchangers with twisted tapes with higher twist ratios. Thus, the friction factor is significantly high in the MHEs comparatively with the BHEs, in consequence of the helical path of the fluid which increases the pressure drop for certain a Reynolds number.

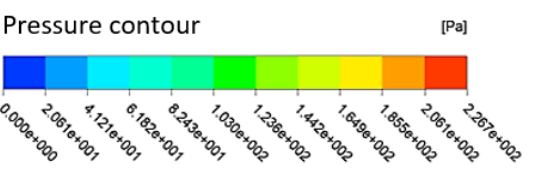

(a)

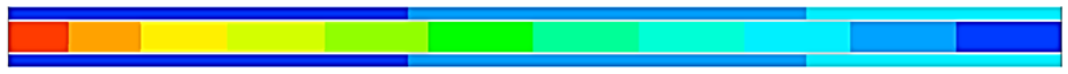

(b)

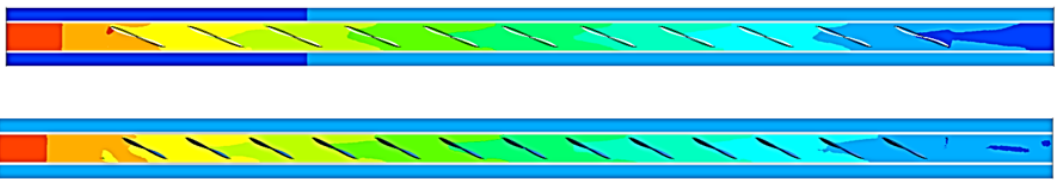

(c)

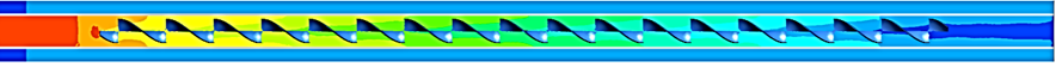

Figure 16. Pressure contour of HEs: (a) Basic HE, (b) Modified HE [ $y / w=7.5]$, (c) Modified HE $[y / w=6]$, (d) Modified HE $[y / w=4.5]$ 


\section{Thermal Performance Factor}

The significance of inserting twisted tape inserts and their twist ratios can be evaluated by a factor thermal performance factor $(\eta)$ for the modified heat exchangers [45]. From the above discussions, it becomes understandable that the smaller twist ratio $(y / w)$ of an insert induces higher heat transfer performance and higher pressure drop which requires more pumping power. Both the heat transfer augmentation and pumping pressure are considered in calculating $\eta$. For the same pumping power for heat exchangers (BHE or MHEs), $\eta$ yields [46]

$$
\eta=\frac{\frac{N u}{N u_{o}}}{\left(\frac{f}{f_{o}}\right)^{\frac{1}{3}}}
$$

Figure 17 illustrates the variation of the thermal performance factor $(\eta)$ as a function of the Reynolds number. For all modified heat exchangers, $\eta$ is found above the unity in both the experimental and numerical investigations. The maximum range of $\eta$, i.e., $\eta=1.197-1.237$, is achieved for the modified HE with the tape inserts with a twist ratio of 4.5 . Conversely, the minimum range of $\eta$, i.e., $\eta=1.0788-1.13$, is identified for the modified HE with the tape inserts with a twist ratio $(y / w)$ of 7.5. So, this figure shows that the main objective of this study is achieved and the insertion of twisted tape inserts in heat exchangers is a promising heat transfer augmentation technique.

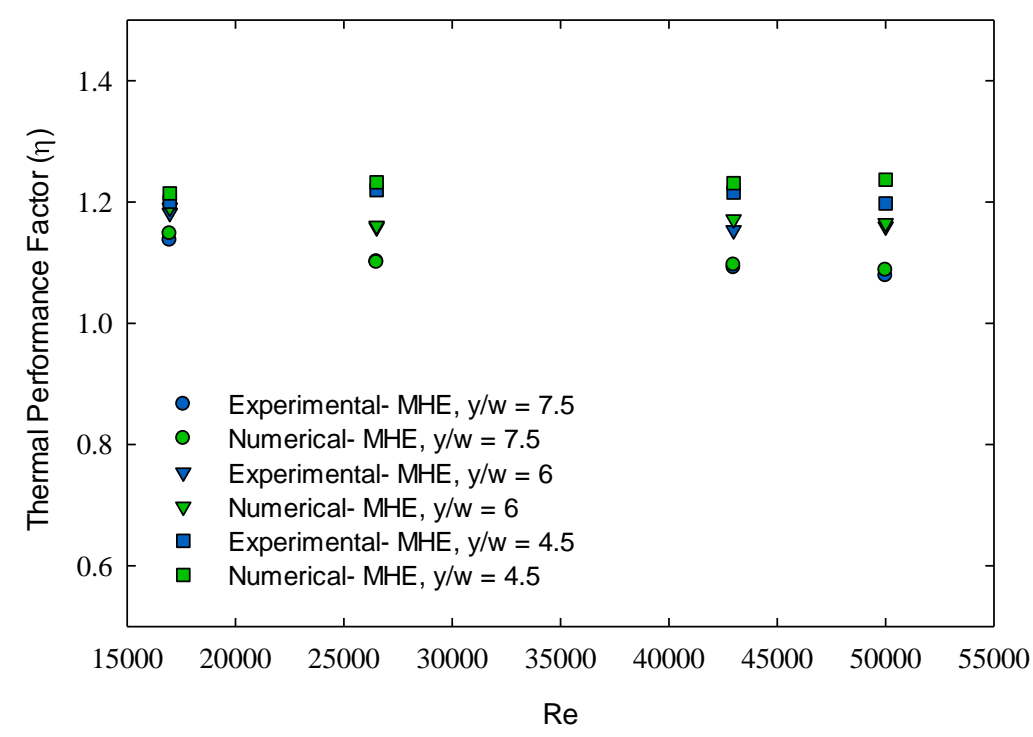

Figure 17. Variation of thermal performance factor as a function of $R e$

\section{CONCLUSION}

Experimental investigation of the present study aims at understanding the effect of variable twist ratios $(y / w)$ of twisted tape on different performance indicators in double tube heat exchangers (HEs) with or without twisted tape inserts by using a variable flow of hot fluid and a constant flow of cold fluid in a closed circuit. Besides, a numerical analysis has been performed by the Renormalization group (RNG) $k-\varepsilon$ turbulence model to visualize the performance enhancement in the heat exchangers with the aid of streamline, velocity contour, temperature contour, and pressure contour. The computations carried out in the developed numerical model show a good agreement with the experimental results. According to the analysis, several conclusions can be listed as follows:

1) The insertion of twisted tapes in a double tube heat exchanger significantly augments the heat transfer performance. The rate of heat transfer augmentation is $\sim 56 \%$ for $\mathrm{HE}$ with TR of $4.5, \sim 27 \%$ for $\mathrm{HE}$ with TR of 6.0 , and $\sim 18 \%$ for HE with TR of 7.5 in the modified heat exchangers (MHEs) compared to that of the basic heat exchanger (BHE).

2) The Nusselt number is found to be increased in the MHEs due to the augmentation in the heat transfer through the inner copper tube wall.

3) The friction factor increases with the increase of the twist density in the twisted tape for MHEs as it narrows the flow field inside the host tube. 
4) The evaluation of the thermal performance factor corroborates the findings of the present study, i.e., the insertion of twisted tape can enhance the heat transfer in heat exchangers. Also, the thermal performance factor increases with a decrease in the twist ratio of the inserted tapes.

5) The developed numerical model can be exploited to reliably predict the heat transfer and fluid flow behavior in double tube heat exchangers with or without twisted tape inserts.

\section{ACKNOWLEDGEMENT}

This work is supported and funded by Ahsanullah University of Science and Technology, Bangladesh.

\section{REFERENCES}

[1] L. Li, Y. Li, and J. Sun, "Prospective fully-coupled multi-level analytical methodology for concentrated solar power plants: Applications," Appl. Therm. Eng., vol. 118, pp. 159-170, 2017.

[2] L. Li, J. Sun, and Y. Li, "Prospective fully-coupled multi-level analytical methodology for concentrated solar power plants: General modelling," Appl. Therm. Eng., vol. 118, pp. 171-187, 2017.

[3] P. Cheppudira Thimmaiah et al., "Performance of finned tubes used in low-pressure capillary-assisted evaporator of adsorption cooling system," Appl. Therm. Eng., vol. 106, pp. 371-380, 2016.

[4] M. M. K. Bhuiya, A. K. Azad, M. S. U. Chowdhury, and M. Saha, "Heat transfer augmentation in a circular tube with perforated double counter twisted tape inserts," Int. Commun. Heat Mass Transf., vol. 74, pp. 18-26, 2016.

[5] M. Soltanimehr and M. Afrand, "Thermal conductivity enhancement of COOH-functionalized MWCNTs/ethylene glycolwater nanofluid for application in heating and cooling systems," Appl. Therm. Eng., vol. 105, pp. 716-723, 2016.

[6] X. Chen, Y. Su, D. Reay, and S. Riffat, "Recent research developments in polymer heat exchangers - A review," Renew. Sustain. Energy Rev., vol. 60, pp. 1367-1386, 2016.

[7] B. Sundén and J. Fu, “Aerospace Heat Exchangers,” Heat Transf. Aerosp. Appl., pp. 89-115, 2017.

[8] K. Nanan, N. Piriyarungrod, C. Thianpong, K. Wongcharee, and S. Eiamsa-ard, "Numerical and experimental investigations of heat transfer enhancement in circular tubes with transverse twisted-baffles," Heat Mass Transf. 2015 5210, vol. 52, no. 10, pp. 2177-2192, 2015.

[9] A. E. Bergles, "Techniques to augment heat transfer," in Handbook of Heat Transfer Applications, 2nd ed., New York: McGraw-Hill, 1985.

[10] F. M. Haidary et al., "Enhancement of pool boiling heat transfer over plain and rough cylindrical tubes," Int. J. Heat Technol., vol. 39, no. 2, pp. 329-336, 2021.

[11] D. Panahi and K. Zamzamian, "Heat transfer enhancement of shell-and-coiled tube heat exchanger utilizing helical wire turbulator," Appl. Therm. Eng., vol. 115, pp. 607-615, 2017.

[12] Z. Feng, X. Luo, F. Guo, H. Li, and J. Zhang, "Numerical investigation on laminar flow and heat transfer in rectangular microchannel heat sink with wire coil inserts," Appl. Therm. Eng., vol. 116, pp. 597-609, 2017.

[13] B. Sajadi, M. M. Najafizadeh, M. Soleimani, M. A. Akhavan Behabadi, and J. Naserinejad, "The effect of wire-coil inserts on the heat transfer and pressure drop of R1234yf flow boiling," Appl. Therm. Eng., vol. 152, pp. 615-623, 2019.

[14] H. Yan, S. Feng, T. Lu, and G. Xie, "Experimental and numerical study of turbulent flow and enhanced heat transfer by crossdrilled holes in a pin-finned brake disc," Int. J. Therm. Sci., vol. 118, pp. 355-366, 2017.

[15] A. Aziz, A. Alsaedi, T. Muhammad, and T. Hayat, "Numerical study for heat generation/absorption in flow of nanofluid by a rotating disk," Results Phys., vol. 8, pp. 785-792, 2018.

[16] R. Capata and A. Beyene, "Experimental evaluation of three different configurations of constructal disc-shaped heat exchangers," Int. J. Heat Mass Transf., vol. 115, pp. 92-101, 2017.

[17] A. J. Modi and M. K. Rathod, "Comparative study of heat transfer enhancement and pressure drop for fin-and-circular tube compact heat exchangers with sinusoidal wavy and elliptical curved rectangular winglet vortex generator," Int. J. Heat Mass Transf., vol. 141, pp. 310-326, 2019.

[18] T. Ambreen, A. Saleem, and C. W. Park, "Pin-fin shape-dependent heat transfer and fluid flow characteristics of water- and nanofluid-cooled micropin-fin heat sinks: Square, circular and triangular fin cross-sections," Appl. Therm. Eng., vol. 158, p. 113781, 2019.

[19] X. Sun, Z. Ye, J. Li, K. Wen, and H. Tian, "Forced convection heat transfer from a circular cylinder with a flexible fin," Int. J. Heat Mass Transf., vol. 128, pp. 319-334, 2019.

[20] A. Sadeghianjahromi, S. Kheradmand, H. Nemati, and C. C. Wang, "Heat transfer enhancement of wavy fin-and-tube heat exchangers via innovative compound designs," Int. J. Therm. Sci., vol. 149, p. 106211, 2020.

[21] M. Omidi, M. Farhadi, and A. Ali Rabienataj Darzi, "Numerical study of heat transfer on using lobed cross sections in helical coil heat exchangers: Effect of physical and geometrical parameters,” Energy Convers. Manag., vol. 176, pp. 236-245, 2018.

[22] S. Yadav and S. K. Sahu, "Heat transfer augmentation in double pipe water to air counter flow heat exchanger with helical surface disc turbulators," Chem. Eng. Process. - Process Intensif., vol. 135, pp. 120-132, 2019. 
[23] W. Cui, D. Mao, B. Lin, and J. Yang, "Field synergy analysis on the mechanism of heat transfer enhancement by using nanofluids," Case Stud. Therm. Eng., vol. 16, p. 100554, 2019.

[24] M. S. Baba, A. V. S. R. Raju, and M. B. Rao, "Heat transfer enhancement and pressure drop of Fe3O4 -water nanofluid in a double tube counter flow heat exchanger with internal longitudinal fins," Case Stud. Therm. Eng., vol. 12, pp. 600-607, 2018.

[25] Z. Said, S. M. A. Rahman, M. El Haj Assad, and A. H. Alami, "Heat transfer enhancement and life cycle analysis of a Shelland-Tube Heat Exchanger using stable CuO/water nanofluid," Sustain. Energy Technol. Assessments, vol. 31, pp. 306-317, 2019.

[26] D. Han, W. F. He, and F. Z. Asif, "Experimental study of heat transfer enhancement using nanofluid in double tube heat exchanger," Energy Procedia, vol. 142, pp. 2547-2553, 2017.

[27] N. T. Ravi Kumar, P. Bhramara, A. Kirubeil, L. Syam Sundar, M. K. Singh, and A. C. M. Sousa, "Effect of twisted tape inserts on heat transfer, friction factor of $\mathrm{Fe} 3 \mathrm{O} 4$ nanofluids flow in a double pipe U-bend heat exchanger," Int. Commun. Heat Mass Transf., vol. 95, pp. 53-62, 2018.

[28] D. Muñoz-Esparza and E. Sanmiguel-Rojas, "Numerical simulations of the laminar flow in pipes with wire coil inserts," Comput. Fluids, vol. 44, no. 1, pp. 169-177, 2011.

[29] S. H. Labib, M. R. A. Himel, J. I. Ali, and A. Goswami, "Study of Heat Transfer Enhancement in Tubular Heat Exchanger with Twisted Tape Inserts," in International Conference on Mechanical, Industrial and Energy Engineering, 2018, pp. ICMIEE18-164(1-6).

[30] J. Zhao, Y. Li, and J. Wang, “A Review on Heat Transfer Enhancement of Borehole Heat Exchanger,” Energy Procedia, vol. 104, pp. 413-418, 2016.

[31] M. E. Nakhchi and J. A. Esfahani, "Numerical investigation of heat transfer enhancement inside heat exchanger tubes fitted with perforated hollow cylinders," Int. J. Therm. Sci., vol. 147, p. 106153, 2020.

[32] R. Andrzejczyk, T. Muszynski, and M. Gosz, "Experimental investigations on heat transfer enhancement in shell coil heat exchanger with variable baffles geometry," Chem. Eng. Process. - Process Intensif., vol. 132, pp. 114-126, 2018.

[33] K. S. Mushatet, Q. A. Rishak, and M. H. Fagr, "Experimental and numerical investigation of swirling turbulent flow and heat transfer due to insertion of twisted tapes of new models in a heated tube," Appl. Therm. Eng., vol. 171, p. 115070, 2020.

[34] W. Liu and B. Bai, "A numerical study on helical vortices induced by a short twisted tape in a circular pipe," Case Stud. Therm. Eng., vol. 5, pp. 134-142, 2015.

[35] W. T. Ji, A. M. Jacobi, Y. L. He, and W. Q. Tao, "Summary and evaluation on single-phase heat transfer enhancement techniques of liquid laminar and turbulent pipe flow," Int. J. Heat Mass Transf., vol. 88, pp. 735-754, 2015.

[36] S. Eiamsa-ard, K. Wongcharee, and S. Sripattanapipat, "3-D Numerical simulation of swirling flow and convective heat transfer in a circular tube induced by means of loose-fit twisted tapes," Int. Commun. Heat Mass Transf., vol. 36, no. 9, pp. 947-955, 2009.

[37] S. Eiamsa-ard, K. Yongsiri, K. Nanan, and C. Thianpong, "Heat transfer augmentation by helically twisted tapes as swirl and turbulence promoters," Chem. Eng. Process. Process Intensif., vol. 60, pp. 42-48, 2012.

[38] H. Bas and V. Ozceyhan, "Heat transfer enhancement in a tube with twisted tape inserts placed separately from the tube wall," Exp. Therm. Fluid Sci., vol. 41, pp. 51-58, 2012.

[39] N. Mashoofi, S. Pourahmad, and S. M. Pesteei, "Study the effect of axially perforated twisted tapes on the thermal performance enhancement factor of a double tube heat exchanger," Case Stud. Therm. Eng., vol. 10, pp. 161-168, 2017.

[40] A. Saysroy and S. Eiamsa-ard, "Enhancing convective heat transfer in laminar and turbulent flow regions using multi-channel twisted tape inserts," Int. J. Therm. Sci., vol. 121, pp. 55-74, 2017.

[41] S. M. Abolarin, M. Everts, and J. P. Meyer, "Heat transfer and pressure drop characteristics of alternating clockwise and counter clockwise twisted tape inserts in the transitional flow regime," Int. J. Heat Mass Transf., vol. 133, pp. 203-217, 2019.

[42] K. Sivakumar, K. Rajan, T. Mohankumar, and P. Naveenchnadran, "Analysis of heat transfer characteristics with triangular cut twisted tape (TCTT) and circular cut twisted tape (CCTT) inserts," Mater. Today Proc., vol. 22, pp. 375-382, 2020.

[43] F. P. Incropera, D. P. Dewitt, T. L. Bergman, and A. S. Lavine, Intorduction to Heat Transfer, 6th ed. 2011.

[44] S. Eiamsa-Ard, P. Somkleang, C. Nuntadusit, and C. Thianpong, "Heat transfer enhancement in tube by inserting uniform/nonuniform twisted-tapes with alternate axes: Effect of rotated-axis length," Appl. Therm. Eng., vol. 54, no. 1, pp. $289-309,2013$.

[45] M. Tusar, A. Noman, M. Islam, P. Yarlagadda, and B. Salam, "CFD study of heat transfer enhancement and fluid flow characteristics of turbulent flow through tube with twisted tape inserts," Energy Procedia, vol. 160, pp. 715-722, 2019.

[46] R. L. Webb, "Performance evaluation criteria for use of enhanced heat transfer surfaces in heat exchanger design," Int. J. Heat Mass Transf., vol. 24, no. 4, pp. 715-726, 1981. 